\title{
Cell wall-related genes studies on peach cultivars with differential susceptibility to woolliness: looking for candidates as indicators of chilling tolerance
}

\author{
Melisa Genero ${ }^{1}$ - Mauro Gismondi ${ }^{1}$ Laura L. Monti ${ }^{1} \cdot$ Julieta Gabilondo $^{2}$. \\ Claudio O. Budde ${ }^{2}$ - Carlos S. Andreo ${ }^{1} \cdot$ María V. Lara $^{1} \cdot$ María F. Drincovich $^{1}$. \\ Claudia A. Bustamante ${ }^{1}$ (D)
}

Received: 17 September 2015/ Accepted: 15 February 2016

(c) Springer-Verlag Berlin Heidelberg 2016

\begin{abstract}
Key message The results obtained indicate that a $\beta$ xylosidase gene may act as good indicator of chilling tolerance and provide new insights into the complex issue of peach fruit woolliness.

Abstract The storage of peaches at low temperatures for prolonged periods can induce a form of chilling injury (CI) called woolliness, characterized by a lack of juiciness and a mealy texture. As this disorder has been associated with abnormal cell wall dismantling, the levels of 12 transcripts encoding proteins involved in cell wall metabolism were analysed in cultivars with contrasting susceptibility to this disorder selected from five melting flesh peach cultivars. The resistant ('Springlady') and susceptible ('Flordaking') cultivars displayed differences in the level of expression of some of the selected genes during fruit softening and in woolly versus non-woolly fruits. From these genes, the level of expression of $P p X y l$, which encodes for a putative $\beta$-xylosidase, was the one that presented the highest correlation (negative) with the susceptibility to woolliness.
\end{abstract}

Communicated by A. Dhingra.

Electronic supplementary material The online version of this article (doi:10.1007/s00299-016-1956-4) contains supplementary material, which is available to authorized users.

Claudia A. Bustamante

bustamante@cefobi-conicet.gov.ar

1 Centro de Estudios Fotosintéticos y Bioquímicos (CEFOBI),

Facultad de Ciencias Bioquímicas y Farmacéuticas,

Universidad Nacional de Rosario, Suipacha 531,

2000 Rosario, Argentina

2 Estación Experimental Agropecuaria San Pedro, Instituto Nacional de Tecnología Agropecuaria (INTA), Ruta

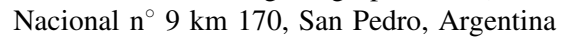

PpXyl expression was also analysed in a cultivar ('Rojo 2') with intermediate susceptibility to woolliness, reinforcing the conclusion about the correlation of $P p X y l$ expression to the presence of woolliness symptom. Moreover, the level of expression of $\mathrm{PpXyl}$ correlated to protein level detected by Western blot. Analyses of the promoter region of the PpXyl gene (1637 bp) isolated from the three cultivars showed no differences suggesting that cis-elements from other regions of the genome and/or trans elements could be responsible of the differential $P p X y l$ expression patterns. Overall, the results obtained indicate that PpXyl may act as a good indicator of woolliness tolerance and that the regulation of expression of this gene in different cultivars does not depend on sequences upstream the coding sequence.

Keywords Cell wall metabolism - Chilling injury ·

Peach $\cdot$ Prunus persica $\cdot$ Woolliness $\cdot$ Xylosidase

$\begin{array}{ll}\text { Abbreviations } \\ \text { ACO1 } & \text { ACC (aminocyclopropane-1-carboxylic acid) } \\ & \text { oxidase 1 } \\ \text { CI } & \text { Chilling injury } \\ \text { CS } & \text { Cold storage } \\ \text { EG } & \text { Endoglucanase } \\ \text { Exp } & \text { Expansin } \\ \text { Gal } & \text { Galactosidase } \\ \text { PG } & \text { Polygalacturonase } \\ \text { PL } & \text { Pectate lyase } \\ \text { PME } & \text { Pectin methylesterase } \\ \text { qRT-PCR } & \text { Quantitative real-time reverse transcription- } \\ & \text { PCR } \\ \text { SL } & \text { Shelf-life } \\ \text { SSC } & \text { Soluble solid content } \\ \text { Xyl } & \text { Xylosidase }\end{array}$




\section{Introduction}

Peaches ripen and deteriorate quickly at room temperature. Therefore, refrigeration is used to slow these processes and to extend fruit market life; however, several fruits can develop chilling injury (CI) during storage at low temperature. CI is genetically influenced and triggered by a combination of the temperature and length of storage (Lurie and Crisosto 2005). In peaches CI includes woolliness (lack of juice) and browning, among other symptoms. It is not possible to detect woolliness from the exterior of the fruit; however, on biting into the fruit the lack of juice results in absence of flavour and a dryness which render it inedible, and leads to consumer dissatisfaction (Brummell et al. 2004b).

During normal ripening, an increase in the activity of cell wall-degrading enzymes is responsible for fruit softening. As peach ripens, several cell wall modifications, such as the solubilisation or depolymerisation of pectin and matrix glycans, are observed, and these changes are of considerable importance in fruit texture (Brummell et al. 2004a). Woolliness (or mealiness) has been associated with abnormal cell wall dismantling during cold storage and the subsequent ripening (Brummell et al. 2004b). It has been proposed that relatively high pectin methylesterase (EC 3.1.1.11) and low endo-polygalacturonase (EC 3.2.1.15) activity in chilling injured fruit leads to an accumulation of de-methylesterified pectins which are not subsequently depolymerized. As a result, the high molecular weight pectins, along with cell wall calcium, form a gel binding free water contributing to the woolliness phenotype (Zhou et al. 2000). In addition, the activities of endo-1,4- $\beta$-glucanase (EC 3.2.1.4), $\beta$-galactosidase (EC 3.2.1.23) and $\alpha$ arabinosidase (EC 3.2.1.55) (Brummell et al. 2004b), and expansin mRNA and protein levels (Obenland et al. 2003) were lower in woolly fruit than in juicy fruit, leading to further alteration of cell wall metabolism.

Although several studies have been performed to improve our knowledge about the molecular basis of CI at cell wall level, most of them were carried out in one cultivar and measuring enzymatic activities (Zhou et al. 2000; Brummell et al. 2004b; Vizoso et al. 2009; Nilo et al. 2010). In the recent years, comparative transcriptomic approaches applied to cold-stored fruits of susceptible and resistant peach cultivars allowed the identification of some cell wall genes involved in CI tolerance, providing possible explanations to chilling resistance (Ogundiwin et al. 2008; Falara et al. 2011; Dagar et al. 2012). In the present work, transcript accumulation of genes involved in cell wall metabolism was determined in peach cultivars with different susceptibility to CI. The objective of the study was to identify candidate genes that could play a role in the tolerance to $\mathrm{CI}$ and provide new insights into the complex issue of peach fruit woolliness. The identification of such key genes, which prime the fruit to cope with chilling stress and may alter fruit mesocarp texture, will likely accelerate the design and the improvement of plant breeding programs.

\section{Materials and methods}

\section{Plant material and post-harvest conditions}

Assays were conducted with peach fruits (Prunus persica cvs 'Springlady', 'Elegant Lady', 'Red Globe', 'Rojo 2', 'Flordaking') grown in the Estación Experimental Agropecuaria INTA, San Pedro, Argentina, during 2009 and harvested in 2010 and repeated with fruits grown during 2010 and harvested in 2011. Relevant agronomic characteristics of the cultivars analyzed are listed in Supplementary Table S1. The flesh firmness of the fruits at harvest was between 45 and $70 \mathrm{~N}$, depending on the cultivar (Table 1). Immediately after harvest, fruits were manually selected for uniformity of colour, size and firmness and divided into two groups: one was kept in a chamber at $20{ }^{\circ} \mathrm{C}$ and $90 \%$ relative humidity for 3 ('Rojo 2'), 4 ('Springlady') or 5 ('Elegant Lady', 'Red Globe', 'Flordaking') days to reach the firmness and organoleptic characteristics suitable for consumption (shelf life, SL group, Table 1). Other group of fruits was stored at $0{ }^{\circ} \mathrm{C}$ and $90 \%$ relative humidity for 21,28 or 35 days followed by the necessary days of each cultivar at $20{ }^{\circ} \mathrm{C}$ to reach organoleptic maturity (CS $+\mathrm{SL}$ group). Samples were taken immediately after harvest $(\mathrm{H})$; after 3, 4 or 5 days in the chamber at $20^{\circ} \mathrm{C}(\mathrm{SL})$; after $21(\mathrm{CS}), 28(\mathrm{CS} 28)$ or 35 (CS35) days at $0{ }^{\circ} \mathrm{C}$; and also after cold storage followed by 3,4 or 5 days at $20^{\circ} \mathrm{C}(\mathrm{CS}+\mathrm{SL}, \mathrm{CS} 28+\mathrm{SL}$, CS35 + SL). About 20-30 fruits from each group were used for colour, firmness, soluble content (SSC) and extractable juice measurements. Representative mesocarp tissue was also collected from the different sample fruit, immediately frozen in liquid nitrogen and stored at $-80{ }^{\circ} \mathrm{C}$ for further experiments.

\section{Determination of fruit quality traits}

Flesh firmness was evaluated with a penetrometer (Effegi 327, Italy) fitted with a $7.9 \mathrm{~mm}$ tip and expressed in Newtons (N). Measurements were carried out on two opposite sides of each individual fruit after removal of the peel. Soluble solid content (SSC) was measured with a refractometer (Atago N1 0-32 ${ }^{\circ}$ Brix). Ground colour was measured on the greenest portion of the peel free of red 
Table 1 Quality attributes of peach cultivars at harvest (H), after harvest and shelf-life (SL), after 21 days at $0{ }^{\circ} \mathrm{C}(\mathrm{CS})$, and after CS plus shelflife $(\mathrm{CS}+\mathrm{SL})$

\begin{tabular}{|c|c|c|c|c|c|}
\hline Cultivar & Parameter & $\mathrm{H}$ & SL & $\mathrm{CS}$ & $\mathrm{CS}+\mathrm{SL}$ \\
\hline \multirow[t]{4}{*}{ ‘Springlady’ } & Firmness (N) & $45.1 \pm 3.9 \mathrm{c}$ & $8.8 \pm 4.9 \mathrm{a}$ & $41.2 \pm 4.9 \mathrm{~b}$ & $4.9 \pm 0.0 \mathrm{a}$ \\
\hline & Ground colour $(\mathrm{H})$ & $84.0 \pm 16.0 \mathrm{c}$ & $73.3 \pm 12.0 \mathrm{a}$ & $83.5 \pm 13.8 \mathrm{bc}$ & $74.1 \pm 10.3 \mathrm{ab}$ \\
\hline & Pulp colour $(\mathrm{H})$ & $95.5 \pm 1.6 \mathrm{~b}$ & $89.9 \pm 2.2 \mathrm{a}$ & $94.8 \pm 0.9 \mathrm{~b}$ & $89.4 \pm 0.8 \mathrm{a}$ \\
\hline & Soluble solids ( ${ }^{\circ}$ Brix) & $11.2 \pm 0.9 \mathrm{~b}$ & $11.5 \pm 0.9 \mathrm{~b}$ & $10.3 \pm 0.8 \mathrm{a}$ & $11.3 \pm 0.9 \mathrm{~b}$ \\
\hline \multirow[t]{4}{*}{ 'Elegant Lady' } & Firmness (N) & $64.7 \pm 4.9 \mathrm{~b}$ & $10.8 \pm 4.9 \mathrm{a}$ & $58.8 \pm 15.7 \mathrm{~b}$ & $6.9 \pm 1.0 \mathrm{a}$ \\
\hline & Ground colour $(\mathrm{H})$ & $84.0 \pm 8.8 b$ & $83.9 \pm 5.1 \mathrm{~b}$ & $80.9 \pm 7.3 b$ & $72.3 \pm 10.4 \mathrm{a}$ \\
\hline & Pulp colour $(\mathrm{H})$ & $93.0 \pm 2.9 \mathrm{~b}$ & $91.4 \pm 3.0 \mathrm{~b}$ & $91.1 \pm 3.0 \mathrm{~b}$ & $86.8 \pm 1.3 \mathrm{a}$ \\
\hline & Soluble solids ( ${ }^{\circ}$ Brix) & $12.9 \pm 0.8 \mathrm{a}$ & $12.6 \pm 0.9 \mathrm{a}$ & $12.8 \pm 1.5 \mathrm{a}$ & $13.1 \pm 0.8 \mathrm{a}$ \\
\hline \multirow[t]{4}{*}{ 'Red Globe' } & Firmness (N) & $72.5 \pm 9.8 \mathrm{c}$ & $27.4 \pm 14.7 \mathrm{~b}$ & $70.6 \pm 5.9 \mathrm{c}$ & $13.7 \pm 10.8 \mathrm{a}$ \\
\hline & Ground colour $(\mathrm{H})$ & $101.2 \pm 2.7 \mathrm{~d}$ & $91.3 \pm 3.3 b$ & $98.2 \pm 3.7 \mathrm{c}$ & $88.2 \pm 2.9 \mathrm{a}$ \\
\hline & Pulp colour $(\mathrm{H})$ & $93.9 \pm 4.5 \mathrm{c}$ & $87.2 \pm 3.2 \mathrm{~b}$ & $89.0 \pm 3.3 \mathrm{~b}$ & $80.4 \pm 3.9 \mathrm{a}$ \\
\hline & Soluble solids ( ${ }^{\circ}$ Brix) & $12.8 \pm 0.9 \mathrm{a}$ & $12.8 \pm 0.9 \mathrm{a}$ & $13.4 \pm 1.3 \mathrm{a}$ & $13.2 \pm 0.9 \mathrm{a}$ \\
\hline \multirow[t]{4}{*}{ ‘Rojo 2’ } & Firmness (N) & $50.0 \pm 3.9 \mathrm{c}$ & $10.8 \pm 4.9 \mathrm{a}$ & $55.9 \pm 5.9 \mathrm{c}$ & $26.5 \pm 10.8 b$ \\
\hline & Ground colour $(\mathrm{H})$ & $72.2 \pm 12.6 \mathrm{c}$ & $28.2 \pm 2.9 \mathrm{a}$ & $81.7 \pm 4.9 \mathrm{~d}$ & $62.1 \pm 8.4 b$ \\
\hline & Pulp colour $(\mathrm{H})$ & $97.2 \pm 2.2 \mathrm{c}$ & $94.3 \pm 2.4 \mathrm{~b}$ & $97.7 \pm 3.3 \mathrm{c}$ & $91.4 \pm 1.5 \mathrm{a}$ \\
\hline & Soluble solids ( ${ }^{\circ}$ Brix) & $8.4 \pm 1.1 \mathrm{a}$ & $9.1 \pm 1.0 \mathrm{a}$ & $8.8 \pm 1.0 \mathrm{a}$ & $8.3 \pm 1.0 \mathrm{a}$ \\
\hline \multirow[t]{4}{*}{ 'Flordaking' } & Firmness $(\mathrm{N})$ & $53.9 \pm 10.8 b$ & $10.8 \pm 2.9 \mathrm{a}$ & $62.7 \pm 10.8 \mathrm{~b}$ & $15.7 \pm 8.8 \mathrm{a}$ \\
\hline & Ground colour $(\mathrm{H})$ & $104.4 \pm 3.3 \mathrm{c}$ & $97.1 \pm 3.1 \mathrm{~b}$ & $101.2 \pm 6.6 \mathrm{c}$ & $91.8 \pm 4.6 \mathrm{a}$ \\
\hline & Pulp colour $(\mathrm{H})$ & $98.9 \pm 3.5 \mathrm{~b}$ & $90.9 \pm 2.2 \mathrm{a}$ & $97.4 \pm 4.6 \mathrm{~b}$ & $88.6 \pm 1.5 \mathrm{a}$ \\
\hline & Soluble solids ( ${ }^{\circ}$ Brix) & $8.8 \pm 0.9 \mathrm{a}$ & $9.9 \pm 1.5 \mathrm{~b}$ & $8.7 \pm 1.1 \mathrm{a}$ & $9.0 \pm 1.1 \mathrm{ab}$ \\
\hline
\end{tabular}

Different letters within each parameter indicate statistically significant differences $(P<0.05)$

blush, and pulp colour was determined on the equatorial zone of a longitudinal section with a chromameter (Minolta CR 300) and recorded as the degrees of hue angle $(\mathrm{H})$. The amount of expressible juice was determined by removing a tissue plug weighing about $2 \mathrm{~g}$ from each fruit with a cork borer, passing it through a $5 \mathrm{~mL}$ syringe into an Eppendorf tube, centrifuging and separately weighing the juice and solids (Lill and Van Der Mespel 1988).

\section{Protein extraction and quantitation}

For SDS-PAGE, proteins were extracted under denaturing conditions from $2 \mathrm{~g}$ of mesocarp as in Borsani et al. (2009). Protein concentration was determined by the method of Bradford (1976) using the Bio-Rad protein assay reagent (Bio-Rad, Hercules, CA, USA) and bovine serum albumin as standard.

\section{Gel electrophoresis}

SDS-PAGE was performed in $10 \%(\mathrm{w} / \mathrm{v})$ polyacrylamide gels according to Laemmli (1970). Proteins were visualized with Coomassie blue or electroblotted onto a nitrocellulose membrane for immunoblotting. Antibodies against Fragaria $\mathrm{x}$ ananassa $\beta$-Xyl (provided by Drs. G. Martínez and P. Civello, IIB-INTECH) were used for detection (1:50 dilution). Bound antibodies were located by linking to alkaline phosphatase-conjugated goat anti-rabbit IgG according to the manufacturer's instructions (Bio-Rad, Hercules, CA, USA).

\section{RNA isolation and reverse transcription}

Total RNA from different samples of peaches was isolated from $4 \mathrm{~g}$ of tissue using the method described by Meisel et al. (2005). The integrity of the RNA was verified by agarose electrophoresis. The quantity and purity of RNA were determined spectrophotometrically. First-strand cDNA was synthesized with MoMLV-reverse transcriptase following the manufacturer's instructions (Promega, Madison, WI, USA) and using $3 \mu \mathrm{g}$ of RNA and oligo(dT).

\section{Quantitative real-time PCR}

Relative expression was determined by performing quantitative real-time PCR (qRT-PCR) in an iCycler iQ detection system with the Optical System Software version 3.0a (Bio-Rad), using the intercalation dye SYBRGreen I (Invitrogen) as a fluorescent reporter, with $2.5 \mathrm{mM} \mathrm{MgCl}$;

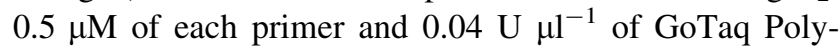
merase (Promega). PCR primers were designed based on peach fruit cDNA sequences published in GenBank and $P$. 
persica expressed sequence tag (EST) databases (TIGR Plant Transcript Assemblies; http://plantta.tigr.org) (Childs et al. 2007), with the aid of the web-based program "primer3" (http://www.frodo.wi.mit.edu/cgi-bin/primer3/pri mer3_www.cgi) in order to produce amplicons of 140-246 bp in size (Supplementary Table S2). The sequences of the primers and amplicons were analysed further using peach EST databases (ESTree Database; http://www.itb.cnr.it/estree/, Lazzari et al. 2008; and GDR Genome Database for Rosaceae, http://www.bioinfo.wsu. edu/gdr/, Jung et al. 2008). A 10-fold dilution of cDNA obtained as described above was used as template. PCR controls were performed in the absence of added reverse transcriptase to ensure RNA samples were free of DNA contamination. Cycling parameters were as follows: initial denaturation at $94{ }^{\circ} \mathrm{C}$ for $2 \mathrm{~min}$; 40 cycles of $96{ }^{\circ} \mathrm{C}$ for $10 \mathrm{~s}, 58{ }^{\circ} \mathrm{C}$ for $15 \mathrm{~s}$ and $72{ }^{\circ} \mathrm{C}$ for $1 \mathrm{~min}$; and $72{ }^{\circ} \mathrm{C}$ for $10 \mathrm{~min}$. Melting curves for each PCR were determined by measuring the decrease of fluorescence with increasing temperature (from 65 to $98{ }^{\circ} \mathrm{C}$ ). The specificity of the PCRs was confirmed by melting curve analysis using the appropriate software as well as by agarose gel electrophoresis of the products. Relative gene expression was

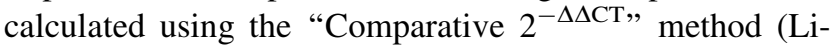
vak and Schmittgen 2001) and DNA-repair enzyme (PpDNArep) as reference gene. Each RNA sample was run in triplicate and repeated in at least two independent sets of treatments generating a total of six replicates per gene per sample. To test whether PpDNArep behaves as housekeeping gene in the analysed samples, the gene expression index was plotted against the sample and linearity and low slope were verified.

\section{Cloning of full-length PpXyl and the promoter region}

Prunus persica full-length cDNA encoding $P p X y l$ was amplified by RT-PCR using RNA extracted from 'Springlady', 'Rojo 2' and 'Flordaking' fruits (Meisel et al. 2005). Amplification was conducted using SuperScript II reverse transcriptase (Invitrogen) and XylF (5'GTCGACCGTCCACCCTTTGCTTG- $3^{\prime}$ ) and XylR (5'GCGGCCGCAACCTTAATTTCTCC- $3^{\prime}$ ) primers. The PCR products were cloned into pGEM-T Easy Vector (Promega) and sequenced.

Genomic DNA was isolated from young peach leaves (cvs 'Springlady', 'Rojo 2', 'Flordaking') according to Dellaporta et al. (1983). Promoter region of the PpXyl gene was cloned by using pXylF (5'-GGAGAAACTCACGCACTCG- $\left.3^{\prime}\right)$ and pXylR (5'-GGACGAGCATGGACAACTC-3') primers. The PCR products were cloned into pGEM-T Easy Vector (Promega) and sequenced.

\section{Bioinformatics analysis}

Putative $\beta$-xylosidase genes were found in the peach genome using the Phytozome database (http://www.phyto zome.org, Goodstein et al. 2012). The number of ESTs identified per gene was determined using peach EST databases (ESTree Database and GDR Genome Database for Rosaceae). Sequence analyses were carried out using the Edit-Seq and Megalign programs included in the DNASTAR 4.05 software package. Glycosyl hydrolase domains were identified in the GeneBank database using the Conserved Domain Database with Reverse Position Specific Blast. Sub-cellular targeting and cleavage site of PpXyl-deduced protein were performed using PSORT (http://psort.nibb.ac.jp/form.html) and SIGNALP (http:// www.cbs.dtu.dk/services/SignalP) software. Potential $\mathrm{N}$-glycosylation sites were studied using NetNGlyc software at http://www.cbs.dtu.dk/services/NetNGlyc/. Identification of putative cis-acting elements was performed using PLANTCARE (http://bioinformatics.psb.ugent.be/ webtools/plantcare/html/) and PlantPAN (http://plantpan. mbc.nctu.edu.tw/gene_group/index.php) software.

\section{Statistical analysis}

Data presented were tested using one-way analysis of variance (ANOVA). Minimum significant differences were calculated by the Bonferroni, Holm-Sidak, Dunett and Duncan tests $(\alpha=0.05)$ using the Sigma Stat Package.

\section{Results}

\section{Identification of peach cultivars with contrasting susceptibility to woolliness}

In order to identify peach cultivars with fruits with differential susceptibility to woolliness, five melting flesh peach cultivars ('Springlady', 'Elegant Lady', 'Red Globe', 'Rojo 2' and 'Flordaking') were examined after ripening at $20{ }^{\circ} \mathrm{C}(\mathrm{SL})$ and after cold storage for 21,28 and 35 days followed by ripening at $20^{\circ} \mathrm{C}(\mathrm{CS}+\mathrm{SL}$, $\mathrm{CS} 28+\mathrm{SL}$ and CS35 + SL). The principal agronomic characteristics of each cultivar are listed in Supplementary Table S1.

During post-harvest ripening of fruits at $20^{\circ} \mathrm{C}$, all peach cultivars displayed a loss of firmness (Table 1). Except for 'Elegant Lady', fruits showed colour changes in both the pulp and the ground of the peel (Table 1). In addition, soluble solids increased during the ripening of 'Flordaking' but were not modified in the other cultivars (Table 1). After cold storage for 21 days (CS), fruit 
maintained their firmness, which rapidly decreased after transfer to $20{ }^{\circ} \mathrm{C}(\mathrm{CS}+\mathrm{SL})$ (Table 1). Soluble solid content did not display a significant variation after cold storage, meanwhile pulp and ground colour showed significant changes (Table 1).

The degree of woolliness, measured as expressible juice, in fruits from the five cultivars was evaluated after storage at $0{ }^{\circ} \mathrm{C}$ for 21,28 or 35 days plus ripening at $20{ }^{\circ} \mathrm{C}$ (Table 2). When fruits were stored for 28 or 35 days, all the cultivars showed less expressible juice in cold-stored samples (CS28 + SL and CS35 + SL) in comparison to SL, indicating that under these conditions all the cultivars presented a woolly texture (Table 2). However, after cold storage for 21 days (CS) fruits from only some cultivars ('Rojo 2' and 'Flordaking') developed a woolly texture, while others ('Springlady', 'Elegant Lady' and 'Red Globe') not (Table 2). When comparing the two susceptible cultivars, 'Flordaking' showed increased woolliness than 'Rojo 2', showing at CS + SL $79.4 \%$ ('Flordaking') and $83.4 \%$ ('Rojo 2') of the expressible juice detected at SL (Table 2). In contrast, in the resistant cultivars ('Springlady', 'Elegant Lady' and 'Red Globe'), expressible juice values were not significant different between $\mathrm{CS}+\mathrm{SL}$ and SL samples. Thus, and based on these results, peach cultivars were classified as more resistant to woolliness ('Springlady', 'Elegant Lady' and 'Red Globe'), intermediate susceptibility to woolliness ('Rojo 2') and more susceptible to woolliness ('Flordaking'). Finally, among the cultivars tested, 'Flordaking' (susceptible to woolliness), 'Rojo 2' (intermediate sensitivity to woolliness) and 'Springlady' (one of the varieties resistant to woolliness that is extensively used in our country) were selected for further studies. The cold storage treatment at $0{ }^{\circ} \mathrm{C}$ for 21 days was selected as the treatment that successfully discriminate the different degree of susceptibility to woolliness among the cultivars (Table 2). After the cold treatment selected, no other chilling injury symptoms, apart from the decrease in expressible juice, were found among the fruits from the different varieties.

\section{Expression of PpACO1 and cell wall-modifying genes in 'Springlady' (resistant to woolliness) and 'Flordaking' (susceptible to woolliness) fruits}

Previous works conducted by other colleagues and by us had shown that the levels of the transcript 1-aminocyclopropane-1-carboxylic acid oxidase 1 (PpACO1), encoding an enzyme involved in ethylene synthesis, are well correlated to ethylene production (Tonutti et al. 1997; Ruperti et al. 2001; Borsani et al. 2009). Thus, the levels of PpACO1 were analyzed by quantitative real-time PCR (qRT-PCR) in 'Springlady' and 'Flordaking' fruits. Figure 1a shows that PpACO1 increases during ripening in both cultivars, and this increase is more pronounced in 'Flordaking' than in 'Springlady' fruits. Peaches stored at $0{ }^{\circ} \mathrm{C}$ for 21 days (CS) displayed practically the same transcript levels than fruits after harvest $(\mathrm{H})$. However, once CS fruits are transferred to $20{ }^{\circ} \mathrm{C}(\mathrm{CS}+\mathrm{SL})$, a rapid increase in $\mathrm{PpACO1}$ occurs, reaching values higher than those found in SL in the case of 'Springlady' and lower in comparison to SL fruits in the susceptible cultivar (Fig. 1a).

In addition, the levels of 12 transcripts encoding proteins involved in cell wall metabolism were investigated by qRT-PCR in the selected cultivars. The genes evaluated were the following: polygalacturonases 1 and 2 (PpPG1-2), expansins 1-3 (PpExp1-3), pectate lyases 1 and 2 (PpPL1$2)$, pectin methylesterases 1 and 2 (PpPME1-2), $\beta$-galactosidase $(P p G a l)$, endo- $\beta$-1,4-glucanase $(P p E G 4)$ and $\beta$ xylosidase $(P p X y l)$. During peach post-harvest softening, transcripts of PpPG1, PpPG2, PpExp2, PpExp3, PpPME2, $P p E G 4$ and $P p X y l$ followed the same trend in 'Springlady' and 'Flordaking' fruits (Fig. 1b). In contrast, PpExp1, PpPL1, PpPL2 and PpGal showed different patterns of expression during ripening, suggesting that the cultivars analyzed present some specificities in relation to softeningrelated cell wall metabolism (Fig. 1b).

After cold storage for 21 days (CS), levels of specific mRNA decreased or remained unchanged with respect to $\mathrm{H}$
Table 2 Expressible juice (\%) after organoleptic maturity at $20{ }^{\circ} \mathrm{C}$ (SL) and after 21,28 or 35 days at $0{ }^{\circ} \mathrm{C}$ plus shelf-life at $20{ }^{\circ} \mathrm{C}(\mathrm{CS}+\mathrm{SL}, \mathrm{CS} 28+\mathrm{SL}$ and CS35 + SL, respectively)

\begin{tabular}{llllr}
\hline Cultivar & SL & CS + SL & CS28 + SL & CS35 + SL \\
\hline $\begin{array}{llll}\text { Expressible juice (\%) } \\
\text { 'Springlady' }\end{array}$ & $62.0 \pm 6.5$ & $60.6 \pm 4.1$ & $35.9 \pm 3.6^{*}$ & $24.9 \pm 4.8^{*}$ \\
'Elegant Lady' & $58.1 \pm 14.6$ & $65.8 \pm 4.3$ & $34.8 \pm 3.6^{*}$ & $25.4 \pm 8.4^{*}$ \\
'Red Globe' & $44.0 \pm 23.9$ & $59.9 \pm 17.2$ & $24.1 \pm 15.1^{*}$ & $5.4 \pm 4.6^{*}$ \\
'Rojo 2' & $68.7 \pm 7.9$ & $57.3 \pm 11.2^{*}$ & $24.5 \pm 8.7^{*}$ & $18.7 \pm 5.8^{*}$ \\
'Flordaking' & $62.1 \pm 8.3$ & $49.3 \pm 9.8^{*}$ & $28.5 \pm 6.6^{*}$ & $35.4 \pm 8.2^{*}$ \\
\hline
\end{tabular}

Asterisks indicate statistically significant differences $(P<0.05)$ when comparing cold-stored $(\mathrm{CS}+\mathrm{SL}$, CS28 + SL and CS35 + SL) versus SL samples 

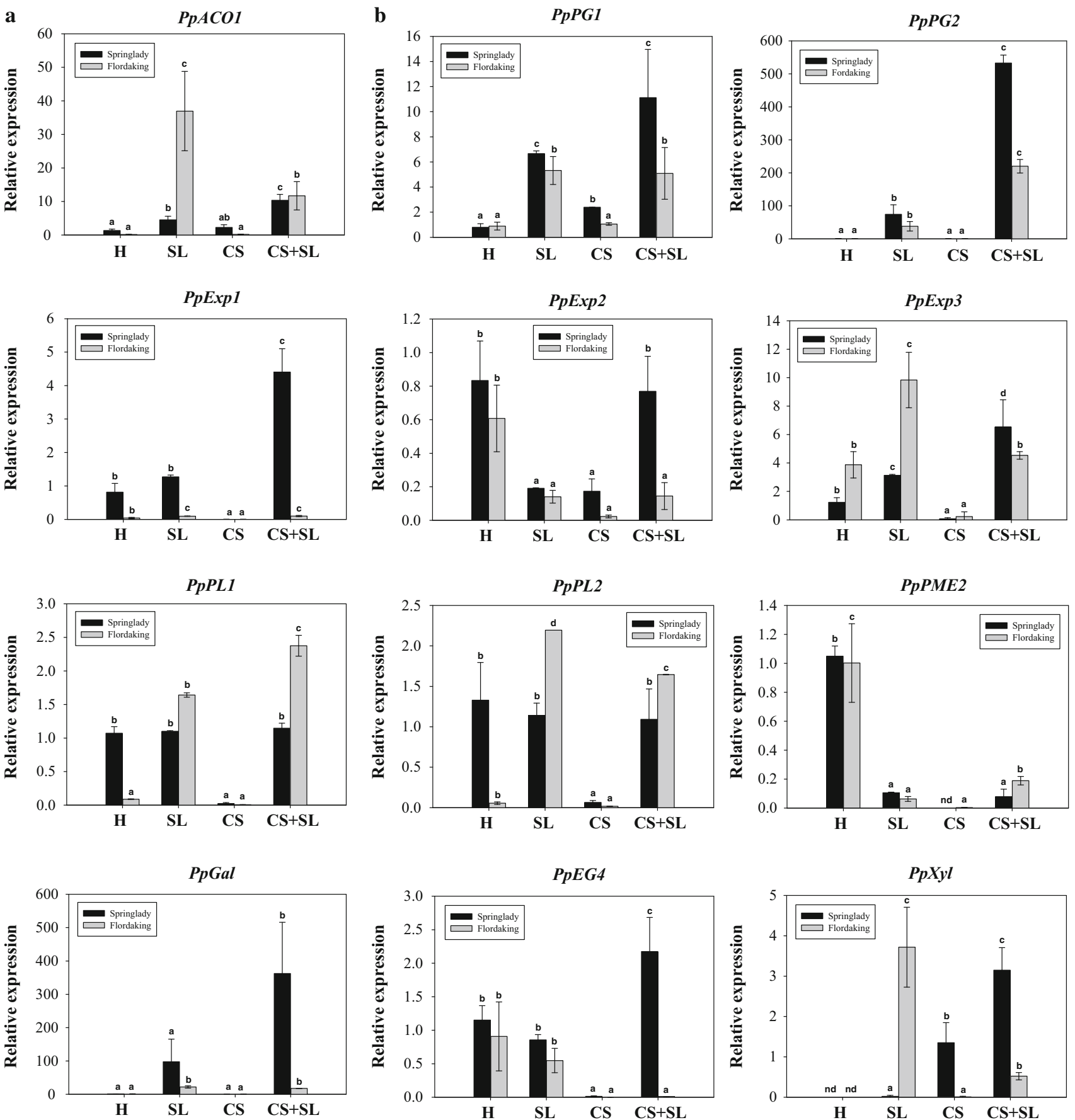

Fig. 1 Levels of PpACO1 and cell wall-modifying transcripts in 'Springlady' and 'Flordaking' fruits kept at $20^{\circ} \mathrm{C}$ or after cold storage. a Level of PpACO1 determined by qRT-PCR. b Level of transcripts encoding proteins involved in cell wall metabolism, assessed by qRT-PCR, during post-harvest ripening or after cold storage. The means of the results obtained, using three independent mRNAs as template, are shown. Each reaction was normalized using

the $C_{t}$ values corresponding to $P$. persica DNA-repair enzyme mRNA. $Y$ axis refers to the fold difference in a particular transcript level relative to its amount found in 'Springlady' peaches after harvest $(\mathrm{H})$. In the case of $\mathrm{PpXyl}$, values are expressed relative to those found in 'Springlady' cultivar kept at $0{ }^{\circ} \mathrm{C}$ for 3 weeks (CS). Standard deviations are shown. For each cultivar, bars with the same letters are not significantly different $(P<0.05)$. nd not detected

in both cultivars, with the exception of $P p X y l$ and $P p P G 1$ in 'Springlady' fruits, where the levels increased in refrigerated peaches (Fig. 1b).
When fruits were transferred to $20{ }^{\circ} \mathrm{C}$ after cold storage $(\mathrm{CS}+\mathrm{SL})$, the level of the transcripts analyzed reached practically the same values or even increased with respect 
Table 3 Gene expression ratio of the transcript levels of selected cell wall genes between CS + SL and SL samples

\begin{tabular}{lcll}
\hline Cell wall gene & \multicolumn{2}{l}{ Ratio $(\mathrm{CS}+\mathrm{SL} / \mathrm{SL})$} \\
\cline { 2 - 4 } & 'Springlady' & 'Rojo 2' & 'Flordaking' \\
\hline PpExp3 & $2.08^{*}$ & $2.63^{*}$ & $0.46^{*}$ \\
PpPL2 & 0.96 & $2.16^{*}$ & $0.75^{*}$ \\
PpEG4 & $2.54^{*}$ & $7.22^{*}$ & $0.02^{*}$ \\
PpXyl & $168.29^{*}$ & $\uparrow$ & $0.14^{*}$ \\
PPPME2 & 0.75 & $5.52^{*}$ & $3.01^{*}$ \\
\hline
\end{tabular}

Asterisks indicate statistically significant differences $(P<0.05)$ when comparing CS + SL and SL samples of each cultivar

$\uparrow$ indicates increase from undetectable levels in SL

to SL, except for PpExp3, PpPL2, PpEG4 and PpXyl, which decreased in 'Flordaking' woolly fruits (Fig. 1b). Transcript levels of PpExp3, PpPL2, PpEG4 and PpXyl decreased by $0.46-, 0.75-, 0.02$ - and 0.14 -fold, respectively, in CS + SL in relation to SL in the susceptible 'Flordaking' cultivar, indicating that these genes could be important for normal ripening process involving disassembly of cell wall material after cold storage (Fig. 1b; Table 3). Moreover, in the resistant cultivar 'Springlady', the comparison of the transcript levels of these genes in CS + SL and SL, indicates that they are not modified (PpPL2) or are increased (PpExp3, $P p E G 4$ and $P p X y l)$ following ripening after cold storage (Fig. 1b; Table 3). It is remarkable the high increase (168.29-fold) of $P p X y l$ in the resistant cultivar 'Springlady' when comparing CS $+\mathrm{SL}$ and SL samples (Table 3).

Finally, we found a 3.01-fold increase in the levels of $P p P M E 2$ when comparing CS $+\mathrm{SL}$ to SL in susceptible 'Flordaking' fruits (Fig. 1b; Table 3). However, PpPME2 remained at the same levels in the resistant cultivar 'Springlady' (Fig. 1b; Table 3). Transcripts of PpPME1 could not be detected in any of the samples analyzed.

\section{Analysis of genes associated with the woolly phenotype in a cultivar with intermediate susceptibility to woolliness}

In 'Flordaking' fruits, the most susceptible cultivar to woolliness found in this study, the levels of expression of PpExp3, PpPL2, PpEG4 and PpXyl in CS + SL samples did not reach the levels detected at SL, suggesting that these genes could be related to the presence of woolliness (Table 3). To gain insight into this hypothesis, transcript levels of PpExp3, PpPL2, PpEG4 and PpXyl were analyzed in 'Rojo 2', a cultivar with intermediate susceptibility to woolliness (Table 2). Figure 2 shows the expression of PpACO1 and the selected genes in 'Rojo 2' fruits. Transcripts of $\mathrm{PpACOI}$ increased during ripening of fruits at room temperature (Fig. 2a). After 21 days at $0{ }^{\circ} \mathrm{C}$
(CS), levels of PpACO1 were higher than in $\mathrm{H}$ fruits, and a further increase was detected after transfer to $20{ }^{\circ} \mathrm{C}$ $(\mathrm{CS}+\mathrm{SL})$ (Fig. 2a).

As shown in Fig. 2b, in 'Rojo 2' the expression of PpExp3, PpPL2, PpEG4 genes was increased and the expression of $P p X y l$ was recovered in CS + SL fruits when compared to SL samples (Fig. 2b; Table 3). When taken together, the level of $P p X y l$ in 'Springlady', 'Rojo 2' and 'Flordaking' in CS + SL fruits, correlated negatively with the presence of woolliness in cold-stored fruits (Figs. 1b, 2b; Table 3).

PPPME2 levels were also determined in 'Rojo 2' cultivar, as this transcript increased in 'Flordaking' but not in 'Springlady' (Fig. 1b; Table 3). Transcripts levels of PPPME2 increased 5.52-fold in CS + SL with respect to SL in this cultivar, showing a gene expression fold change even higher than that found in 'Flordaking' fruits (Fig. 2b; Table 3).

\section{PpXyl protein levels during ripening and after cold storage}

In order to analyze PpXyl protein levels in resistant ('Springlady'), moderately susceptible ('Rojo 2') and susceptible ('Flordaking') cultivars, Western blot analysis was performed by using antibodies against $\beta$-Xyl ( $\beta$-Xylosidase) from Fragaria x ananassa (Bustamante et al. 2006). In agreement with qRT-PCR results, in 'Springlady', PpXyl protein was undetectable after ripening (SL), while in 'Flordaking' cultivar, it increased in SL samples with respect to $\mathrm{H}$ (Fig. 3). In 'Rojo 2', PpXyl was undetectable after harvest $(\mathrm{H})$ but increased slightly when fruits were stored at $20^{\circ} \mathrm{C}$ for 3 days (SL).

After cold storage (CS), PpXyl protein levels correlated with the tolerance to woolliness, being undetectable in 'Flordaking' fruits and higher in 'Springlady' than in 'Rojo 2' cultivar (Fig. 3). When fruits were transferred to $20^{\circ} \mathrm{C}$ $(\mathrm{CS}+\mathrm{SL}), \mathrm{PpXyl}$ protein levels increased in the three cultivars.

\section{Cloning of PpXyl coding sequence and bioinformatics analysis of the putative protein}

Seven putative $\beta$-Xyl genes can be deduced from peach genome: ppa001718m (PpXyl), ppa001656m, ppa001675m, ppa001692m, ppa023763m, ppa001583m, ppa015037m (Supplementary Table S3). The number of ESTs found in databases indicated that just three of these genes are expressed in mesocarp tissue, being PpXyl the most represented (Ogundiwin et al. 2008; Falara et al. 2011).

The full-length cDNA of $P p X y l$ encodes a primary translation product of 776 amino acid residues, with a 

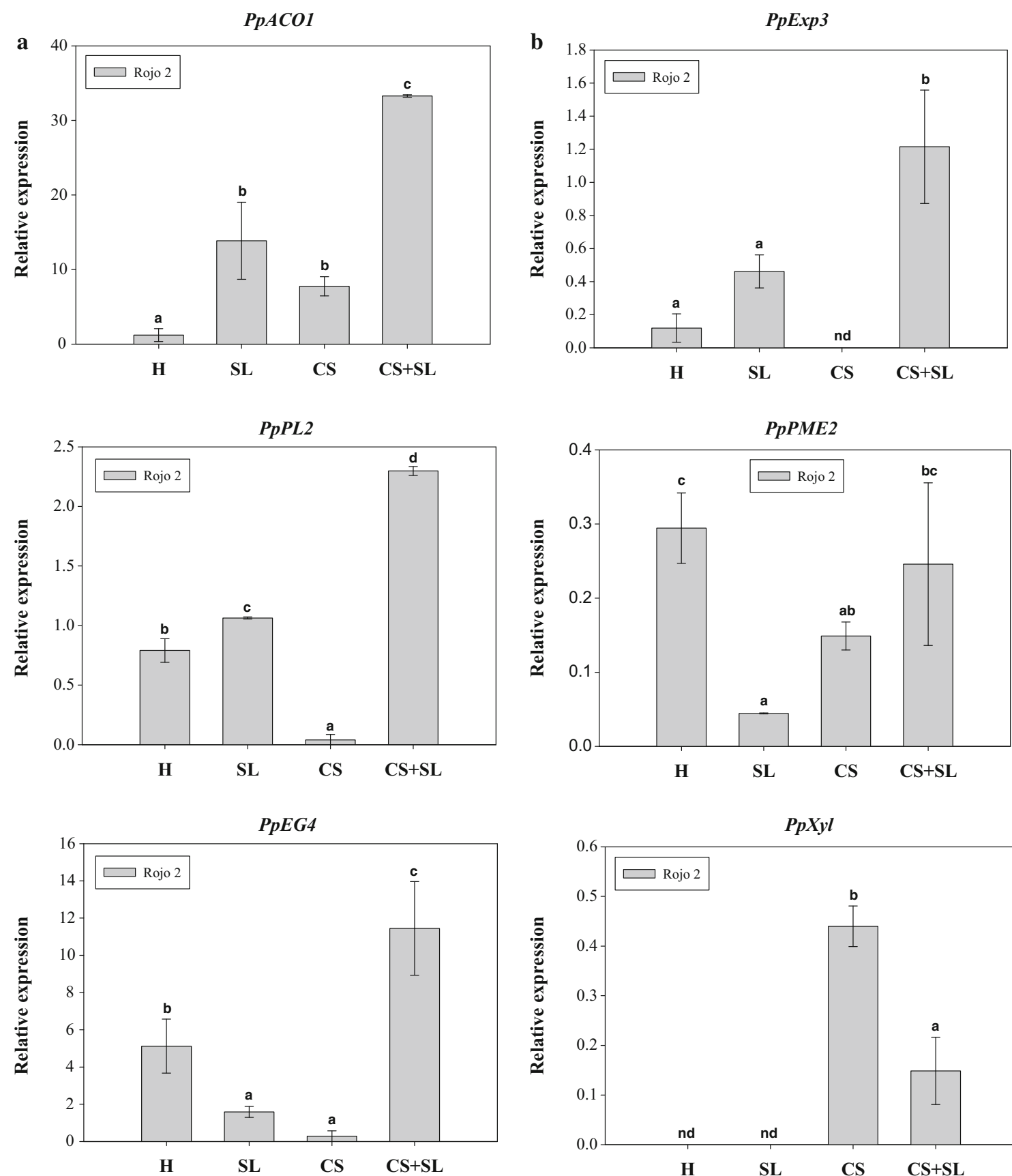

Fig. 2 Levels of PpACO1 and candidate gene transcripts in 'Rojo 2' fruits kept at $20^{\circ} \mathrm{C}$ or after cold storage. a Level of PpACO1 determined by qRT-PCR. b Transcript levels of PpExp3, PpPL2, $P p P M E 2, P p E G 4$ and $P p X y l$ genes, assessed by qRT-PCR, during post-harvest ripening or after cold storage. The means of the results obtained, using three independent mRNAs as template, are shown. Each reaction was normalized using the $C_{t}$ values corresponding to $P$.

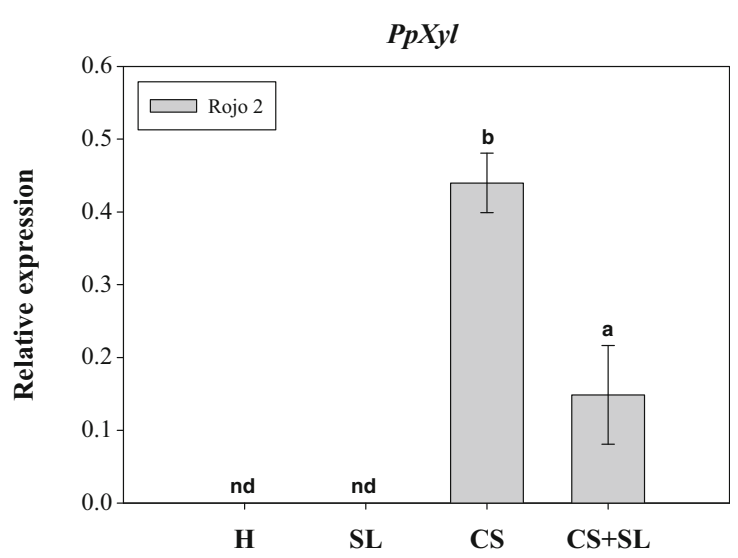

persica DNA-repair enzyme mRNA. $Y$ axis refers to the fold difference in a particular transcript level relative to its amount found in 'Springlady' peaches after harvest $(\mathrm{H})$. In the case of $P p X y l$, values are expressed relative to those found in 'Springlady' cultivar kept at $0{ }^{\circ} \mathrm{C}$ for 3 weeks (CS). Standard deviations are shown. Bars with the same letters are not significantly different $(P<0.05)$. $n d$ not detected

predicted molecular mass of $84 \mathrm{kDa}$. To look for changes in PpXyl protein sequence in 'Springlady', 'Rojo 2' and 'Flordaking' fruits, the coding region of the gene from the three cultivars was cloned and sequenced. However, no differences in the sequence of the transcripts were found

among the cultivars analyzed and the one published in GenBank (XM_007225606).

Protein encoded by $\mathrm{PpXyl}$ shows high degree of identity with sequences of $\beta$-xylosidase proteins from Prunus salicina (98.2\%), Malus domestica (85.5\%), Pyrus 


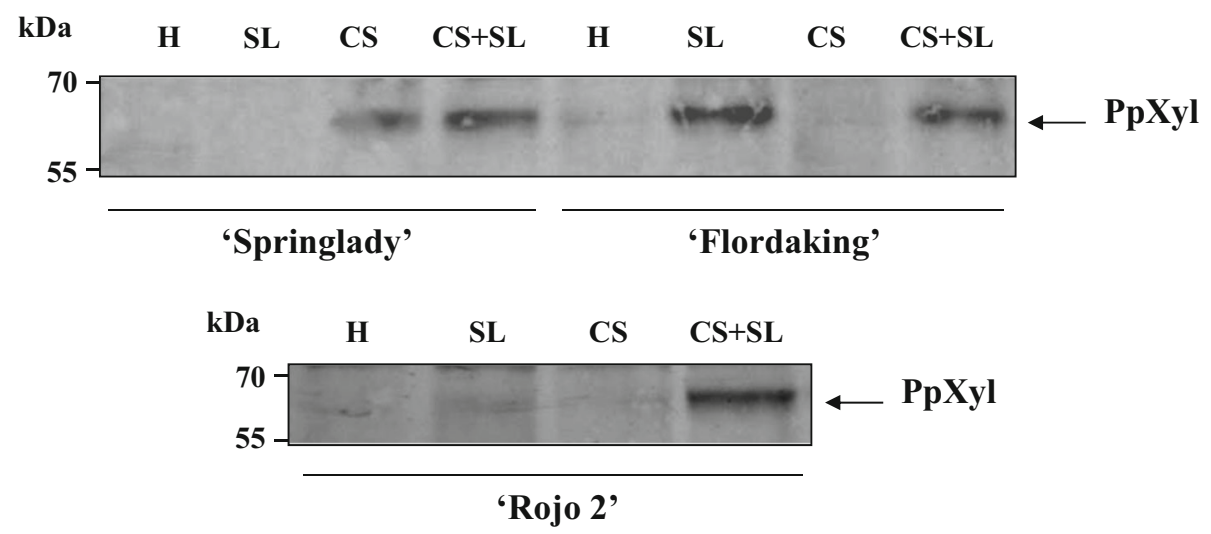

Fig. 3 Western blot analysis of $\beta$-Xyl protein. Levels of $\beta$-Xyl protein during ripening and after cold storage of 'Springlady', 'Rojo 2 ' and 'Flordaking' fruits. $\beta$-Xyl is shown by immunoblotting using antibodies against $\beta$-Xyl from Fragaria $\times$ ananassa. Twenty

pyrifolia (85.5\%) and Fragaria x ananassa (83.9\%), among others (Supplementary Table S4). Conserved domains, which are present in glycosyl hydrolase family 3, are present in the deduced amino acid sequence of PpXyl from peach (Supplementary Fig. S1a). PSORT, SIGNALP and NetNGlyc software predict a 28 -amino acid signal peptide that targets $\mathrm{PpXyl}$ for secretion and the presence of two potential sites of $\mathrm{N}$-glycosilation (Bustamante et al. 2012).

\section{Cloning and sequence features of the PpXyl promoter region}

A fragment of $1637 \mathrm{bp}$ of the region upstream of the translation start codon of $P p X y l$ was isolated from 'Springlady', 'Rojo 2' and 'Flordaking' genomic DNA, and a promoter motif search was performed to reveal putative cis-acting elements (Supplementary Fig. S1b, Supplementary Table S5). Sequences obtained from the three cultivars, and the one obtained from peach genome (GDR Genome Database for Rosaceae), were identical, indicating the absence in this region of putative regulatory sequences that may be responsible for the differential patterns of expression observed, especially after cold storage (Figs. 1b, 2b; Table 3).

The sequence analysis detected the presence of a putative TATA-box at $35 \mathrm{bp}$ from the transcription start site. Potential regulatory elements associated with hormone, light and stress-related responses were also found (Supplementary Fig. S1b, Supplementary Table S5). Putative hormone responsive elements identified in the PpXyl promoter region include an ABRE motif (ABA response), an AuxRE motif (involved in auxin responsiveness), a CPB element (citokinin response), two motifs involved in gibberellin (GA) response (GARE and GAMYB), an ERE micrograms of protein extracted from peach fruit were added per lane. Marker bands are shown on the left $(\mathrm{kDa})$. Coomassie brilliant blue-stained gels were loaded with equivalent amounts of the samples used in the western blots and served as a loading control (not shown)

element (ethylene response) and a Py-box (GA and ABA coordinated response) (Supplementary Table S5). The cisacting elements involved in light responses include a SORLIP motif, a SORLEP element, a REbeta motif, a T-box and a G-box site. In addition, the $P p X y l$ promoter sequence contains $c i s$-elements related to stress responses, included a CRT/DRE motif (involved in low-temperature responses) and a P1BS element (involved in phosphate starvation signalling). Finally, a number of transcription factor binding sites (MYC, MYB, MYB4, RAV1) and cisacting elements involved in sugar repression (SRE) and circadian expression (CIRCADIAN) were also identified (Supplementary Fig. S1b, Supplementary Table S5).

\section{Discussion}

There is a large variation among peach cultivars in their susceptibility to $\mathrm{CI}$ when stored at $0{ }^{\circ} \mathrm{C}$; in general, early season yellow-fleshed cultivars are less susceptible to CI than later season cultivars (Crisosto et al. 1999). In the present work, we gained insight into some molecular basis of this diversity in susceptibility by selecting five commercial peach cultivars (Supplementary Table S1) with differential susceptibility and evaluating the response of cell-wall related genes to postharvest refrigeration. Contrary to what was expected, after 21 days at $0{ }^{\circ} \mathrm{C}$ plus ripening at $20{ }^{\circ} \mathrm{C}$, the two early season cultivars ('Rojo 2' and 'Flordaking') presented a woolly phenotype, meanwhile the mid ('Springlady' and 'Red Globe') and late ('Elegant Lady') season cultivars were resistant to CI (Table 2).

During ripening of 'Springlady' and 'Flordaking' cultivars at $20^{\circ} \mathrm{C}, P p P G 1, P p P G 2, P p E x p 3$ and $P p X y l$ genes exhibited an increase in transcript accumulation (Fig. 1b) 
that matched with ethylene production, as accounted for the increase in PpACO1 transcript levels (Fig. 1a; Tonutti et al. 1997; Ruperti et al. 2001; Borsani et al. 2009), and fruit softening (Table 1). In addition, transcripts of PpExp2 and $P P P M E 2$ genes decreased during ripening of fruits, meanwhile $P p E G 4$ mRNA remained unchanged. PpExpl, $P p P L 1, P p P L 2$ and $P p G a l$ genes followed different trends depending on the cultivar analyzed (Fig. 1b).

Cold storage slows down the ripening process, preventing PpACO1 accumulation (Fig. 1a) and loss of firmness (Table 1). Accordingly, transcripts of cell wall-related genes decreased or remained at the same levels after storage at $0{ }^{\circ} \mathrm{C}$ for 3 weeks in comparison to $\mathrm{H}$ fruits, with the exception of PpXyl and PpPGI in 'Springlady' cultivar (Fig. 1b). After transfer to $20^{\circ} \mathrm{C}(\mathrm{CS}+\mathrm{SL})$, fruit firmness declined in both cultivars (Table 1) and the expression of the cell wall-related genes reached the same values or even increased with respect to SL, except for PpExp3, PpPL2, $P p E G 4$ and $P p X y l$ in 'Flordaking' (woolly fruits). Thus, the expression of PpExp3, PpPL2, PpEG4 and PpXyl genes could be related to the tolerance of peach fruit to low temperature (Fig. 1b; Table 3). Results obtained for PpEG4 gene are in agreement with Brummell et al. (2004b), who demonstrated that after cold storage and ripening, the activity of endo-1,4- $\beta$-glucanase (EC 3.2.1.4), among other enzymes, was lower in mealy than in juicy fruit. A possible role of $\beta$-xylosidase gene in the tolerance to CI has been previously suggested by Falara et al. (2011) in peach fruit, as this gene also showed higher transcript levels in a tolerant cultivar in comparison to a susceptible one. In tomato, the $\beta$-xylosidase LeXyl2 is up-regulated at low temperatures suggesting a possible role of the protein in fruit defence against the incidence of CI symptoms (Page et al. 2010; Müller et al. 2013). Recently, it was reported that a reduction in the transcription of a $P L$ gene can contribute to the development of peach woolliness (González-Agüero et al. 2008), and a similar role could be expected for PpPL2. Similar results were also obtained by Vizoso et al. (2009) when comparing the expression of a PL gene in woolly and juicy fruits. As PpPL2, the expression of this gene decreases in cold stored fruits with respect to unripe samples, but follows a different trend during fruit softening, suggesting that the PL identified by the authors would not be encoded by PpPL2. In relation to expansins, Obenland et al. (2003) observed that the expression of expansin mRNA and protein was strongly suppressed in mealy tissue, indicating a possible role for expansin in the development of this disorder. In this work, only PpExp3 seems to be involved in the appearance of the woolly phenotype (Fig. 1b).

Woolliness has been attributed to high PME and low PG activities after CS (Lurie and Crisosto 2005). However, no correlation or differences between PG and PME activities and woolliness development have been found in all cases (Artes et al. 1996; Manganaris et al. 2008). In 'Springlady', PpPME2 transcript levels did not change in CS $+\mathrm{SL}$ in relation to SL fruits; meanwhile, in 'Flordaking', transcript levels of PPPME2 increased in CS + SL with respect to SL, suggesting that the demethylation of the polyuronides could play a role in the development of woolliness in 'Flordaking' fruits (Fig. 1b; Table 3). In 'O'Henry' fruits, a CI susceptible cultivar, similar results were obtained for a PME-like protein, as the transcript levels of the gene increased in woolly fruits when compared to juicy fruits (Vizoso et al. 2009). PpPG1 and PpPG2 transcript accumulation remained at the same levels or increased, respectively, in CS + SL with respect to SL fruits in both cultivars, indicating that the mRNA levels of these genes did not correlate with the tolerance to CI (Fig. 1b). Transcript levels of PpExp1, PpExp2, PpPL1 and PpGal genes do not seem to correlate with woolliness development as these genes showed the same levels or even increased in CS + SL fruits in comparison to SL fruits, in both cultivars (Fig. 1b).

With the aim to aid into the role of PpExp3, PpPL2, $P p P M E 2, P p E G 4$ and $P p X y l$ in the tolerance to woolliness appearance, transcript levels of these genes were also tested by qRT-PCR in 'Rojo 2', a cultivar with intermediate susceptibility to woolliness (Fig. 2b). For PpExp3, PpPL2 and PpEG4 no correlation between mRNA levels in refrigerated fruits and differential susceptibility to woolliness was observed. However, in the case of PpXyl, transcript levels could act as a good indicator of tolerance to woolliness in peach fruit (Table 3). PpXyl mRNA accumulation correlated with differential susceptibility to CI after cold storage (Fig. 2b). In addition, transcript levels of PpXyl increased notoriously (168.29-fold), moderately (from 0 to 0.15 ) and decreased (7.13-fold) in CS $+\mathrm{SL}$ fruits in comparison to SL in 'Springlady', 'Rojo 2' and 'Flordaking' cultivars, respectively (Table 3 ). This correlation was also confirmed at protein level in CS samples (Fig. 3). In the case of PpPME2, an increase in transcript levels was detected in woolly fruits ('Rojo 2' and 'Flordaking'); however, no as clear relationship as $P p X y l$ between PpPME2 mRNA levels and the degree of CI (woolliness) was observed (Table 3).

Promoter region of the $P p X y l$ gene was cloned from 'Springlady', 'Rojo 2' and 'Flordaking' genomic DNA in order to investigate the presence of differential putative regulatory sequences. However, the fragment cloned was identical in the three cultivars analyzed, suggesting that cis-elements present in other regions of the genome or trans elements could be responsible of the differential pattern of expression of the gene. Additionally, other regulatory mechanisms, such as epigenetic or posttranscriptional modifications, are also possible. The sequence 
analysis suggests that the $P p X y l$ gene could be regulated by a number of hormones. In this sense, Hayama et al. (2006) demonstrated the transcriptional regulation of the gene by ethylene in 'Manami' cultivar, which is in accordance with the presence of an ERE motif in the three cultivars analyzed (Supplementary Fig. S1b, Supplementary Table S5). Pons et al. (2014) reported that auxins may play a role in regulating the differential response of peach fruits to cold. These results, along with the presence of an AuxRE motif in the promoter region of the gene, suggest that auxins could be contributing to the differences found in the transcription levels of $P p X y l$ in the tested cultivars (Supplementary Fig. S1b, Supplementary Table S5). In addition, a cis-element associated with cold stress-inducible gene expression (CRT/DRE) was found, which could be responsible of the increase in $P p X y l$ transcript levels after cold storage, in relation to $\mathrm{H}$ fruits (Supplementary Fig. S1b, Supplementary Table S5). CBF (C-repeat Binding Factor) transcription factors, which are induced by low temperatures, bind to this cis-element to regulate a large number of cold-regulated (COR) genes (the $\mathrm{CBF}$ regulon) which products are thought to contribute to freezing tolerance (Artlip et al. 2013). Thus, the different patterns of expression of $P p X y l$ observed in the cultivars analyzed could be regulated by the levels of CBFs produced in each cultivar at low temperatures (Liang et al. 2013).

The PpXyl protein contains 776 amino acid residues and has a predicted molecular mass of $84 \mathrm{kDa}$. This value is higher than the apparent molecular mass found by Western-blot analysis. Similar results were obtained for $\beta$-xylosidases from strawberry fruits (Bustamante et al. 2006), stems of Arabidopsis thaliana (Minic et al. 2004) and seedlings of Hordeum vulgare (Lee et al. 2003). In the latter case, the authors proved the processing of $\mathrm{COOH}$ terminal portion of the primary translation product during maturation. Probably, in peach fruit, such a deletion could also occur, causing the reduction of molecular mass from $84 \mathrm{kDa}$, predicted from cDNA, to the value observed by Western blot (Fig. 3).

$\beta$-D-xylosidases are responsible for the hydrolysis of xylans liberating $\beta$-D-xylosyl residues (Itai et al. 2003). These genes have been implicated in fruit softening (Martínez et al. 2004), plant development (Goujon et al. 2003) and hydrolysis of cell wall polysaccharides in response to sugar starvation (Lee et al. 2007). In this work, we propose that $P p X y l$ could also play a role in determining different tolerance to $\mathrm{CI}$ and that the expression of this gene after cold storage could act as indicator of tolerance to the incidence of one of the most important CI symptoms, as it is woolliness.

Author contribution statement COB, CSA, MVL, MFD and $C A B$ conceived and designed research. MG,
MGi, LLM, JG and CAB conducted experiments. MG, $\mathrm{MGi}$ and $\mathrm{CAB}$ analyzed data. $\mathrm{CAB}$ wrote the manuscript. All authors read and approved the manuscript.

Acknowledgments This work was supported by Agencia Nacional de Promoción de Actividades Científicas y Técnicas (Argentina, PICT 2010-0097). CSA, MVL, MFD and CAB are members of the Researcher Career of CONICET and MGi and LLM are fellows of the same Institution. JG and COB are members of INTA. The authors thank Drs. G. Martínez and P. Civello (IIB-INTECH) for kind gift of the anti- $\beta$-Xyl antibody.

\section{Compliance with ethical standards}

Conflict of interest The authors declare that they have no conflict of interest.

\section{References}

Artes F, Cano A, Fernandez-Trujillo JP (1996) Pectolytic enzyme activity during intermittent warming storage of peaches. J Food Sci 61:311-313

Artlip TS, Wisniewski ME, Bassett CL, Norelli JL (2013) CBF gene expression in peach leaf and bark tissues is gated by a circadian clock. Tree Physiol 33:866-877

Borsani J, Budde CO, Porrini L, Lauxmann MA, Lombardo VA, Murray R, Andreo CS, Drincovich MF, Lara MV (2009) Carbon metabolism of peach fruit after harvest: identification of key enzymes involved in organic acid and sugar level modifications. J Exp Bot 60:1823-1837

Bradford M (1976) A rapid and sensitive method for the quantification of microgram quantities of protein utilizing the principle of protein-dye binding. Anal Biochem 72:248-254

Brummell DA, Dal Cin V, Crisosto CH, Labavitch JM (2004a) Cell wall metabolism during maturation, ripening and senescence of peach fruit. J Exp Bot 55:2029-2039

Brummell DA, Dal Cin V, Lurie S, Crisosto $\mathrm{CH}$, Labavitch JM (2004b) Cell wall metabolism during the development of chilling injury in cold-stored peach fruit: association of mealiness with arrested disassembly of cell wall pectins. J Exp Bot 55:2041-2052

Bustamante CA, Rosli HG, Añón MC, Civello PM, Martínez GA (2006) $\beta$-Xylosidase in strawberry fruit: isolation of a full-length gene and analysis of its expression and enzymatic activity in cultivars with contrasting firmness. Plant Sci 171:497-504

Bustamante CA, Budde CO, Borsani J, Lombardo VA, Lauxmann MA, Andreo CS, Lara MV, Drincovich MF (2012) Heat treatment of peach fruit: modifications in the extracellular compartment and identification of novel extracellular proteins. Plant Physiol Biochem 60:35-45

Childs KL, Hamilton JP, Zhu W, Ly E, Cheung F, Wu H, Rabinowicz PD, Town CD, Buell CR, Chan AP (2007) The TIGR plant transcript assemblies database. Nucleic Acids Res 35:D846D851

Crisosto CH, Mitchell FG, Ju Z (1999) Susceptibility to chilling injury of peach, nectarine, and plum cultivars grown in California. HortScience 34:1116-1118

Dagar A, Friedman H, Lurie S (2012) Utilization of chillpeach microarray platform for comparing chilling injury-susceptible 'hermoza' and chilling injury-resistant 'oded' peaches. Acta Hortic 945:337-344 
Dellaporta SL, Wood J, Ticks JB (1983) A plant molecular DNA minipreparation version 2. Plant Mol Biol Rep 1:19-21

Falara V, Manganaris GA, Ziliotto F, Manganaris A, Bonghi C, Ramina A, Kanellis AK (2011) A $\beta$-D-xylosidase and a PR-4B precursor identified as genes accounting for differences in peach cold storage tolerance. Funct Integr Genomic 11:357-368

González-Agüero M, Pavez L, Ibáñez F, Pacheco I, Campos-Vargas R, Meisel LA, Orellana A, Retamales J, Silva H, González M (2008) Identification of woolliness response genes in peach fruit after post-harvest treatments. J Exp Bot 59:1973-1986

Goodstein DM, Shu S, Howson R, Neupane R, Hayes RD, Fazo J, Mitros T, Dirks W, Hellsten U, Putnam N, Rokhsar DS (2012) Phytozome: a comparative platform for green plant genomics. Nucleic Acids Res 40:D1178-D1186

Goujon T, Minic Z, El Amrani A, Lerouxel O, Aletti E, Lapierre C, Joselau J, Jouanin L (2003) AtBXL1, a novel higher plant (Arabidopsis thaliana) putative $\beta$-xylosidase gene, is involved in secondary cell wall metabolism and plant development. Plant $\mathrm{J}$ 33:677-690

Hayama H, Shimada T, Fujii H, Ito A, Kashimura Y (2006) Ethyleneregulation of fruit softening and softening-related genes in peach. J Exp Bot 57:4071-4077

Itai A, Ishihara K, Bewley D (2003) Characterization of expression, and cloning, of $\beta$-D-xylosidase and $\alpha$-L-arabinofuranosidase in developing and ripening tomato (Lycopersicon esculentum Mill.) fruit. J Exp Bot 54:2615-2622

Jung S, Staton M, Lee T, Blenda A, Svancara R, Abbott A, Main D (2008) GDR (Genome Database for Rosaceae): integrated webdatabase for Rosaceae genomics and genetics data. Nucleic Acids Res 36:D1034-D1040

Laemmli UK (1970) Cleavage of structural proteins during the assembly of the head of bacteriophage T4. Nature 227:680-685

Lazzari B, Caprera A, Vecchietti A, Merelli I, Barale F, Milanesi L, Stella A, Pozzi C (2008) Version VI of the ESTree db: an improved tool for peach transcriptome analysis. BMC Bioinformatics 9:S9

Lee RC, Hrmova M, Burton RA, Lahnstein J, Fincher GB (2003) Bifunctional family 3 glycoside hydrolases from barley with $\alpha$-Larabinofuranosidase and $\beta$-D-xylosidase activity. J Biol Chem 278:5377-5387

Lee EJ, Matsumura Y, Soga K, Hoson T, Koizumi N (2007) Glycosyl hydrolases of cell wall are induced by sugar starvation in Arabidopsis. Plant Cell Physiol 48:405-413

Liang L, Zhang B, Yin X-R, Xu C-J, Sun C-D, Chen K-S (2013) Differential expression of the CBF gene family during postharvest cold storage and subsequent shelf-life of Peach fruit. Plant Mol Biol Rep 31:1358-1367

Lill RE, Van Der Mespel GJ (1988) A method for measuring the juice content of mealy nectarines. Sci Hortic 36:267-271

Livak KJ, Schmittgen TD (2001) Analysis of relative gene expression data using real-time quantitative PCR and the $2^{-\Delta \Delta C T}$. Methods 25:402-408

Lurie S, Crisosto CH (2005) Chilling injury in peach and nectarine. Postharvest Biol Technol 37:195-208

Manganaris GA, Vicente AR, Crisosto CH, Labavitch JM (2008) Cell wall modifications in chilling-injured plum fruit (Prunus salicina). Postharvest Biol Technol 48:77-83
Martínez GA, Chaves AR, Civello PM (2004) $\beta$-xylosidase activity and expression of a $\beta$-Xylosidase gene during strawberry fruit ripening. Plant Physiol Biochem 42:89-96

Meisel L, Fonseca B, González S, Baezayates R, Cambiazo V, Campos R, Gonzalez M, Orellana A, Retamales J, Silva H (2005) A rapid and efficient method for purifying high quality total RNA from peaches (Prunus persica) for functional genomics analyses. Biol Res 38:83-88

Minic Z, Rihouey C, Trung Do C, Lerouge P, Jouanin L (2004) Purification and characterization of enzymes exhibiting $\beta$-Dxylosidase activities in stem tissues of Arabidopsis. Plant Physiol $135: 1-12$

Müller GL, Budde CO, Lauxmann MA, Triassi A, Andreo CS, Drincovich MF, Lara MV (2013) Expression profile of transcripts encoding cell wall remodelling proteins in tomato fruit cv. Micro-Tom subjected to $15^{\circ} \mathrm{C}$ storage. Funct Plant Biol 40:449-458

Nilo R, Saffie C, Liley K, Baeza-Yates R, Cambiazo V, CamposVargas R, González M, Meisel MA, Retamales J, Silva H, Orellana A (2010) Proteomic analysis of peach fruit mesocarp softening and chilling injury using difference gel electrophoresis (DIGE). BMC Genom 11:43

Obenland DM, Crisosto CH, Rose JKC (2003) Expansin protein levels decline with the development of mealiness in peaches. Postharvest Biol Technol 29:11-18

Ogundiwin EA, Marti C, Forment J, Pons C, Granell A, Gradziel TM, Peace CP, Crisosto CH (2008) Development of ChillPeach genomic tools and identification of cold-responsive genes in peach fruit. Plant Mol Biol 68:379-397

Page D, Gouble B, Valot B, Bouchet JP, Callot C, Kretzchmar A, Causse M, Renard CMCG, Faurobert M (2010) Protective proteins are differentially expressed in tomato genotypes differing for their tolerance to low-temperature storage. Planta 232:483-500

Pons C, Martí C, Forment J, Crisosto CH, Dandekar AM, Granell A (2014) A bulk segregant gene expression analysis of a peach population reveals components of the underlying mechanism of the fruit cold response. PLoS One 9:e90706

Ruperti B, Bonghi C, Rasori A, Ramina A, Tonutti P (2001) Characterization and expression of two members of the peach 1-aminocyclopropane-1-carboxylate oxidase gene family. Physiol Plantarum 111:336-344

Tonutti P, Bonghi C, Ruperti B, Tornielli GB, Ramina A (1997) Ethylene evolution and 1-aminocyclopropane-1-carboxylate oxidase gene expression during early development and ripening of peach fruit. J Am Soc Hortic Sci 122:642-647

Vizoso P, Meisel LA, Tittarelli A, Latorre M, Saba J, Caroca R, Maldonado J, Cambiazo V, Campos-Vargas R, Gonzalez M, Orellana A, Silva H (2009) Comparative EST transcript profiling of peach fruits under different post-harvest conditions reveals candidate genes associated with peach fruit quality. BMC Genom 10:423-440

Zhou HW, Ben-Arie R, Lurie S (2000) Pectin esterase, polygalacturonase and gel formation in peach pectin fractions. Phytochem 55:191-195 